Supplement of Biogeosciences Discuss., 11, 10605-10646, 2014

http://www.biogeosciences-discuss.net/11/10605/2014/

doi:10.5194/bgd-11-10605-2014-supplement

(C) Author(s) 2014. CC Attribution 3.0 License.

(c) (i)

Supplement of

\title{
A halocarbon survey from a seagrass dominated subtropical lagoon, Ria Formosa (Portugal): flux pattern and isotopic composition
}

I. Weinberg et al.

Correspondence to: I. Weinberg (ingo.weinberg@zmaw.de) 
Supplement of Biogeosciences Discuss., 11, 10605-10646, 2014

http://www.biogeosciences-discuss.net/11/10605/2014/

doi:10.5194/bgd-11-10605-2014-supplement

(C) Author(s) 2014. CC Attribution 3.0 License.

(c) (i)

Supplement of

\section{A halocarbon survey from a seagrass dominated subtropical lagoon, Ria Formosa (Portugal): flux pattern and isotopic composition}

I. Weinberg et al.

Correspondence to: I. Weinberg (ingo.weinberg@zmaw.de) 


\section{SUPPLEMENTARY}

\section{A halocarbon survey from a seagrass dominated subtropical lagoon, Ria Formosa (Portugal): Flux pattern and isotopic composition}

Ingo Weinberg*, Enno Bahlmann, Tim Eckhardt, Walter Michaelis, and Richard Seifert

University of Hamburg, Institute for Biogeochemistry and Marine Chemistry,

Bundesstraße 55, 20146 Hamburg, Germany

*corresponding author:_ingo.weinberg@zmaw.de

phone: +49-40-42838-9170

fax: $\quad+49-40-42838-6347$

\section{Design of cryotraps used for air and seawater samples (Purge and trap)}

The analytic procedure is based on those of Bahlmann et al. (2011) for the isotopic determination of trace gases with some adjustments. We changed the design of the cryotraps in order to establish a better temporal resolution by reducing the sample preparation/analysis time. The self-made cryotraps were $1 / 4$ " siltek capillary $(40 \mathrm{~cm})$ connected to a stainless steel capillary $(60 \mathrm{~cm})$ and were bowed forming a U-shape. This allows the cryotrap being easily submersed in the dry shipper (Voyageur 12, Air Liquide, Germany) as cooling source during sampling. The cryotraps were filled with Tenax TA (20-35 mesh, $5 \mathrm{~cm}$, Grace, Deerfield, USA) at the lower end of $1 / 4$ " capillary and fixed with silanized glass wool at the top and bottom of the packing material. The inlet and outlet were capped with Swagelok fittings and endcaps allowing rapid connection and closure before/after sampling and measurements.

\section{Measurement of air and seawater samples}

The measurement procedure for air and water samples was as follows (Fig. A1): 


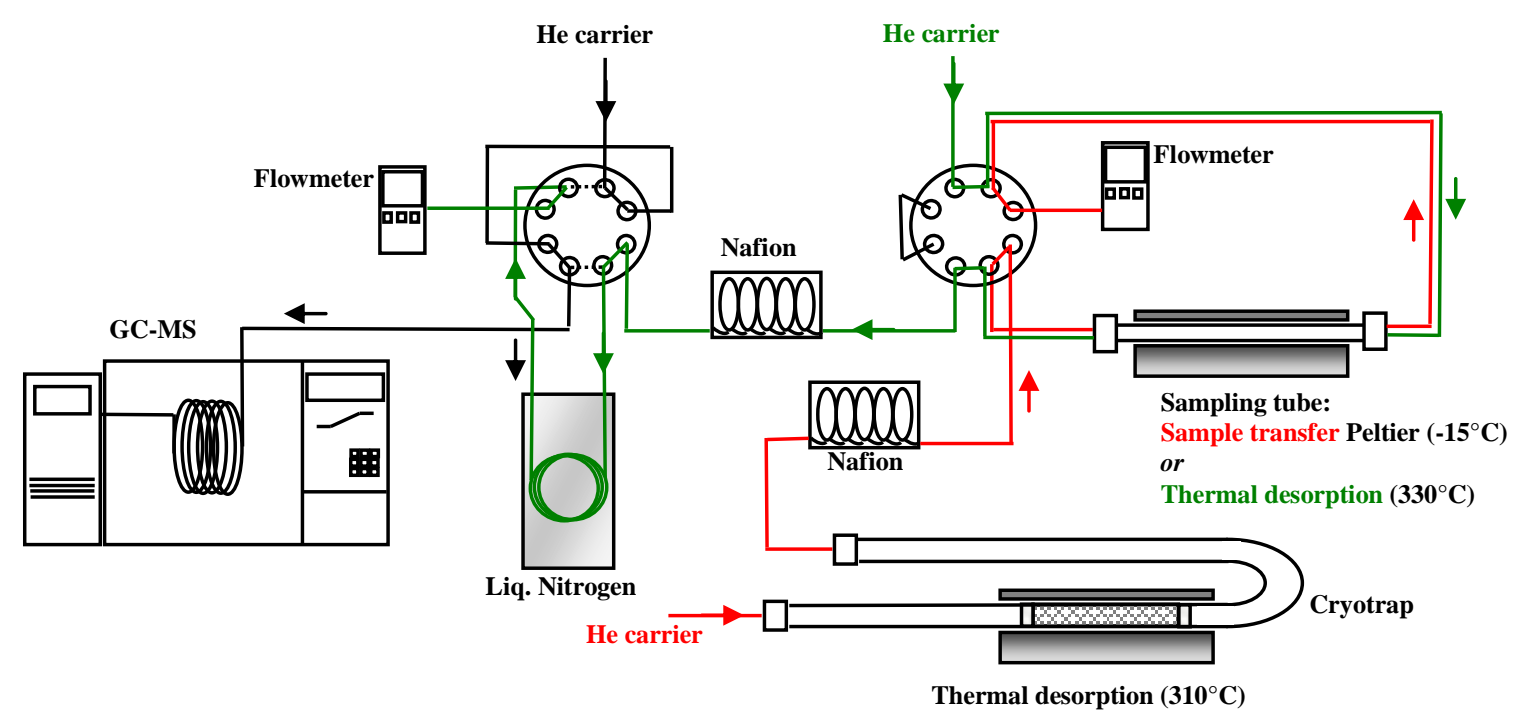

Fig. A1: Scheme of the analytical system for the determination of halocarbons from air and water samples.

After sampling (air sampling or purge\&trap of water samples), the samples were thermally desorbed from the cryotrap $\left(310^{\circ} \mathrm{C}\right)$ under a flow of high-purity helium $\left(50 \mathrm{~mL} \mathrm{~min}{ }^{-1}\right.$, 99.999\%, Linde, Germany) for $15 \mathrm{~min}$ (red lines/arrows). The analytes were re-trapped on peltier-cooled sampling tubes (Bahlmann et al., 2011) at $-15^{\circ} \mathrm{C}$ using a Valco eight port valve (VICI, Valco instruments, Houston, USA). After sample transfer, the valco valve was switched and analytes were thermally desorbed $\left(330^{\circ} \mathrm{C}\right)$ from the adsorbent tubes in counterflow direction $\left(\mathrm{He}, 30 \mathrm{~mL} \mathrm{~min}^{-1}\right)$, here indicated as green lines/arrows. During the desorption (20 min), the analytes were then refocused on a cryotrap (quartz capillary, $60 \mathrm{~cm}, 0.32$ i.d.) submerged in liquid nitrogen. The refocusing of analytes and injection into the GC-MS system proceeds using a second eight port valco valve. After retrapping, the valve is switched and compounds are sent to the GC-MS system in counterflow direction (black (dotted) lines/arrows) under ambient temperature. Due to high water amounts in air and water samples, the water was removed by two Nafion dryers (in silica gel), each after thermal desorption from the cryotraps and the adsorbent tubes.

The GC-MS (6890N/5975B, Agilent, Waldbronn, Germany) was equipped with a CPPorabondQ column $\left(25 \mathrm{~m}, 0.25 \mu \mathrm{m}\right.$ i.d., Varian). The flowrate was set to $3^{\circ} \mathrm{mL}$. The oven temperature program was as follows: $40{ }^{\circ} \mathrm{C}$, hold $4 \mathrm{~min} ; 12^{\circ} \mathrm{C} \mathrm{min}^{-1}$ to $200^{\circ} \mathrm{C}$, hold $2 \mathrm{~min}$, $8^{\circ} \mathrm{C} \mathrm{min}^{-1}$ to $240^{\circ} \mathrm{C} ; 30^{\circ} \mathrm{C} \mathrm{min}^{-1}$ to $280^{\circ} \mathrm{C}$, hold $5 \mathrm{~min}$. The MS was operated in the electron impact mode at $70 \mathrm{eV}$. Temperatures of quadrupole, source, and transfer line were $150^{\circ} \mathrm{C}$, $230^{\circ} \mathrm{C}$, and $250^{\circ} \mathrm{C}$. Acquisition was executed in full scan mode $(33-300 \mathrm{u})$. Target analytes were identified by their retention times and respective mass spectra and quantified using their major mass fragments. Quantification of air and water samples was done by using aliquots of 
Scott EPA TO 15/17 gas standard (1 ppm in nitrogen, Sigma Aldrich, Germany) and $\mathrm{CH}_{3} \mathrm{I}$ gas standard (100 ppm in nitrogen, Air Liquide, Germany) injected to the GC-MS.

The trapping and desorption efficiency (recovery rates) of the cryotraps was tested $(n=4)$. $2 \mathrm{~mL}$ of Scott EPA TO 15/17 gas standard (1 ppm in nitrogen) and $20 \mu \mathrm{L} \mathrm{CH}_{3} \mathrm{I}(100 \mathrm{ppm}$ nitrogen) was injected to the cryotraps submerged in the dry shipper using a stream of helium. Simulating "real" air sampling, helium was stream was set to $1 \mathrm{~L} \mathrm{~min}{ }^{-1}$ for $30 \mathrm{~min}$ (resulting in $30 \mathrm{~L}$ ). The whole sample treatment procedure was applied as described above. The mean recovery rates of a suite of halocarbons were $96 \%$ ranging from $93 \pm 4 \%\left(\mathrm{CH}_{3} \mathrm{Br}\right)$ and $93 \pm$ $10 \%\left(\mathrm{CCl}_{4}\right)$ to $100 \pm 4 \%$ for $\mathrm{CHBr}_{3}$. Individual recovery rates are displayed in Fig. A2.

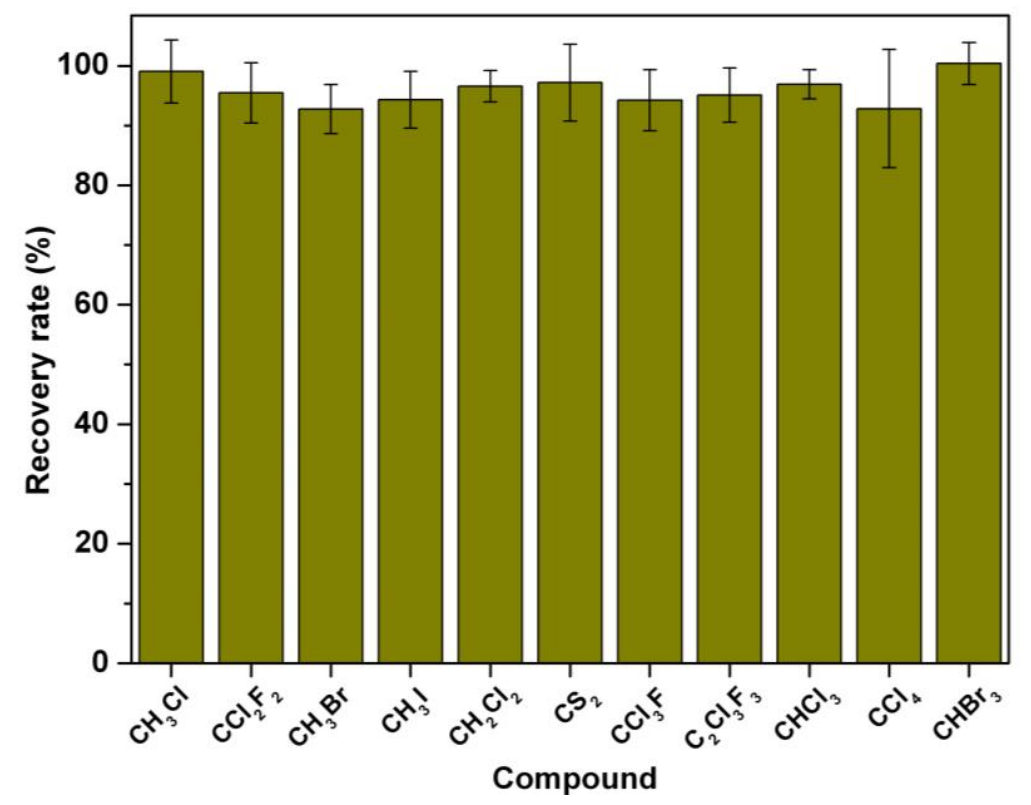

Fig. A2: Mean recovery rates and their absolute standard deviations of halocarbons from recovery experiments $(n=4)$.

\section{References}

Bahlmann, E., Weinberg, I., Seifert, R., Tubbesing, C., and Michaelis, W.: A high volume sampling system for isotope determination of volatile halocarbons and hydrocarbons, Atmos. Meas. Tech., 4, 2073-2086, 10.5194/amt-4-2073-2011, 2011. 